Case Series

\title{
Spinal Cord Stimulation Inhibits Cortical Somatosensory Evoked Potentials Significantly Stronger than Transcutaneous Electrical Nerve Stimulation
}

Tilman Wolter, MD, Kristin Kieselbach, MD, Ronen Sircar, MD, and Mortimer Gierthmuehlen, MD

From: Interdisciplinary Pain Center, University Hospital Freiburg, Freiburg Germany

Address Correspondence: Tilman Wolter, MD University Hospital Freiburg Interdisciplinary Pain Center Breisacherstr. 64 Freiburg, Germany E-mail: tilman.wolter@uniklinikfreiburg.

Disclaimer: There was no external funding in the preparation of this manuscript. Conflict of interest: Dr. Wolter has received a single travel grant from Boston Scientific in 2010.

Manuscript received: 01-17-2013 Revised manuscript received: 03-09-2013 Accepted for publication: 0319-2013

Free full manuscript: www.painphysicianjournal.com
Background: Despite the good clinical results elicited by spinal cord stimulation (SCS), the physiological basis of action of SCS is widely unknown. Inhibition of somatosensory evoked potential (SEP) amplitudes by SCS has been described, but it is unclear whether this displays dose dependency. Moreover, it is unknown whether the pain-relieving effect elicited by SCS correlates with the inhibition of SEPs. Finally, this study aimed to answer the question whether there is a difference in the effect on SEPs between SCS and transcutaneous electrical nerve stimulation (TENS), thus between central nervous system stimulation and peripheral nervous system stimulation.

Methods: Ten patients (4 men and 6 women, age range 40-77 years) with neuropathic lower limb pain were included in the study. All patients had implanted SCS systems with percutaneous type electrodes. Cortical SEPs under SCS and TENS were measured without stimulation, under stimulation at perception threshold (PT), and at maximal threshold (MT) in a crossover design.

Results: Cortical SEP amplitudes were significantly inhibited by SCS. Stimulation at PT and at MT both led to a statistically significant inhibition of the SEP amplitude. The difference between amplitude reduction at PT and MT showed a tendency towards significance. The degree of SEP amplitude inhibition did not correlate with pain relief. Inhibition of SEP amplitudes by TENS was weaker than that elicited by SCS. The average percentage of amplitude reduction at MT was twice as high under SCS as it was under TENS. No effects on SEP latencies were seen.

Conclusions: SCS exerts a significantly stronger inhibition of SEP amplitudes than TENS. The data hint at a dose dependency of SCS-induced SEP amplitude inhibition. No correlation between SEP amplitude inhibition and pain relief was found.

Key words: spinal cord stimulation, SCS, transcutaneous electrical nerve stimulation, TENS, neuropathic pain, somatosensory evoked potentials, SEP

Pain Physician 2013; 16:405-414

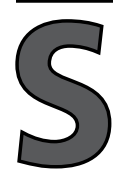
pinal cord stimulation (SCS) has been successfully employed in the treatment of neuropathic pain for more than 3 decades (1) and beneficial effects have been described in various neuropathic pain conditions such as failed back surgery syndrome (2-6), Complex Regional Pain Syndrome (CRPS) (7-9), and post-herpetic neuralgia $(2,10)$. Despite the good clinical results elicited by SCS, the physiological basis of the pain-relieving effect of SCS is widely unknown (11).
The inhibitory effect of SCS on somatosensory evoked potentials (SEPs) has been described in a number of studies (12-14). However it is unknown whether this effect is dose dependent. Moreover it is not clear whether or not this effect correlates with the clinical efficacy of SCS (14). The dose dependency of the clinical pain-relieving effect has recently been demonstrated (15).

In recent years, new stimulation therapies focusing on the peripheral nerve system have arisen. Subcutane- 
ous or peripheral nerve field stimulation (16) has been proposed for the treatment of various pathologies such as post-laminectomy syndrome (17), post-thoracotomy pain (18), groin pain (19), and post-herpetic neuralgia (20). Thus in some clinical situations, such as groin pain or post-herpetic neuralgia, both SCS and subcutaneous stimulation are possible. In these situations the use of the more invasive SCS should be weighed according to advantages, such as possibly higher clinical efficacy. Up to now, although not explicitly, SCS therapy has always followed the notion that it is more effective to stimulate the spinal cord (thus the central nervous system) than to stimulate the peripheral nervous system, as for instance with transcutaneous electrical stimulation (TENS).

The present study addressed the following questions:

- Is the inhibition of SEPs elicited by neurostimulation dose dependent?

- Does the pain-relieving effect elicited by SCS correlate with the inhibition of SEPs?

- Is there a difference of the effect on SEPs between SCS (central nervous system stimulation) and TENS (peripheral nervous system stimulation)?

\section{Methods}

\section{Patients}

Criteria for eligibility were SCS for neuropathic pain with significant pain relief, capacity to understand the study design, and willingness to fill in pain questionnaires. Exclusion criteria were myocardial infarction in the preceding 3 months (due to the risk of reinfarction), cerebral ischemia in the preceding 3 months, and degenerative central nervous system disease (due to the possible impact on SEPs).

\section{Questionnaires}

All patients completed a pain questionnaire including items regarding the mean, minimal, maximal, and tolerable level of pain on an numerical rating scale (NRS) in the 2 weeks prior to baseline.

\section{Study Design and Interventions}

Patients were physically examined at baseline. The stimulation pattern and the settings of the SCS device were recorded. Perception thresholds in supine, sitting, and standing positions were registered. The patients had switched off the stimulator for at least one hour prior to the SEP recording. The experimental setting is described in Fig. 1.

\section{SCS and TENS Application}

SCS was performed at the intensity and impulse duration which the patients routinely used. Stimulation parameters and threshold are displayed in Table 1.

TENS was applied on the painful leg. TENS electrodes were fixed at the medial side of the foot and at the medial side of the lower leg approximately 15 $\mathrm{cm}$ above the ankle. TENS was applied with continuous impulses at the same frequency as SCS. The intensity of stimulation with the TENS device (Arthrostim Select, ORMED GmbH, Freiburg, Germany) was regulated on a 0-60 scale in 0.5 steps. The impulse duration was determined on this scale. The maximum value (60) corresponded to an impulse duration of $250 \mu \mathrm{s}$. Maximal effective current under these conditions and at a maximal voltage of $40 \mathrm{~V}$ (depending on the individual electrical tissue resistance) was $23 \mathrm{~mA}$. TENS thresholds are displayed in Table 1.

\section{SEP Recordings}

The SEP recordings were performed with the patient lying in a supine position. SEP recordings were conducted with an ISIS IOM Neuromonitoring System (Inomed Medizintechnik GmbH, Emmendingen, Germany). Transcutaneous tibial nerve stimulation was done with biphasic square-wave pulses of $0.2 \mathrm{~ms}$ at a frequency of $5.3 \mathrm{~Hz}$ with the cathode placed proximally at the medial ankle of the painful leg. The stimulation intensity was chosen slightly above motor threshold. Cortical SEP recordings were done using scalp electrodes placed at $\mathrm{Fz}$ and $\mathrm{Cz}$. Two series of 1,000 stimuli were averaged for each measurement. First, one measurement without stimulation was done, then (within 30-60 sec) one measurement under SCS at perception threshold (PT) (defined as the lowest intensity the patient could perceive) followed by one measurement at maximal threshold (MT) (defined as the highest intensity the patient would rate as not painful). After a short pause (2-3 min), identical measurements were performed under TENS. Five patients had measurements of SCS followed by measurements of TENS and 5 patients vice-versa. The allocation to these 2 groups was random (Fig. 1).

\section{Statistical Analysis}

Computer software packages (GraphPad Prism, Version 5.01, GraphPad Software, Inc. La Jolla, USA, and R, Version 2.11.1, R Foundation for Statistical Computing, Vienna, Austria) were used for statistical analyses. First descriptive statistics were computed for all items. Due to the small number of observations, non-parametric 

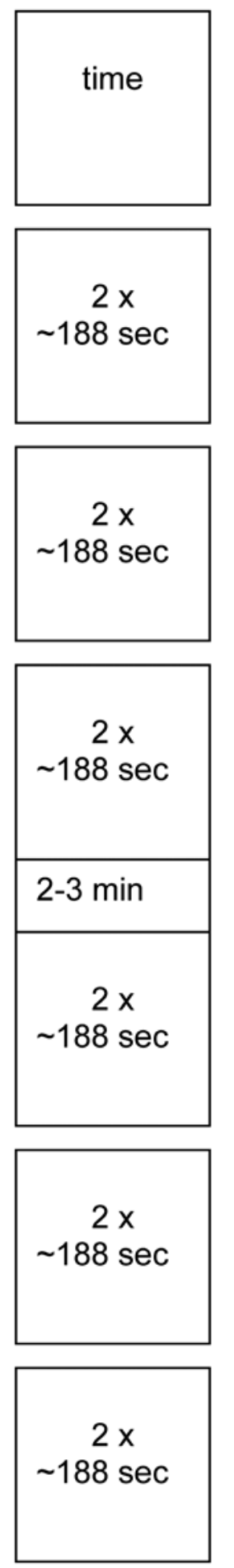
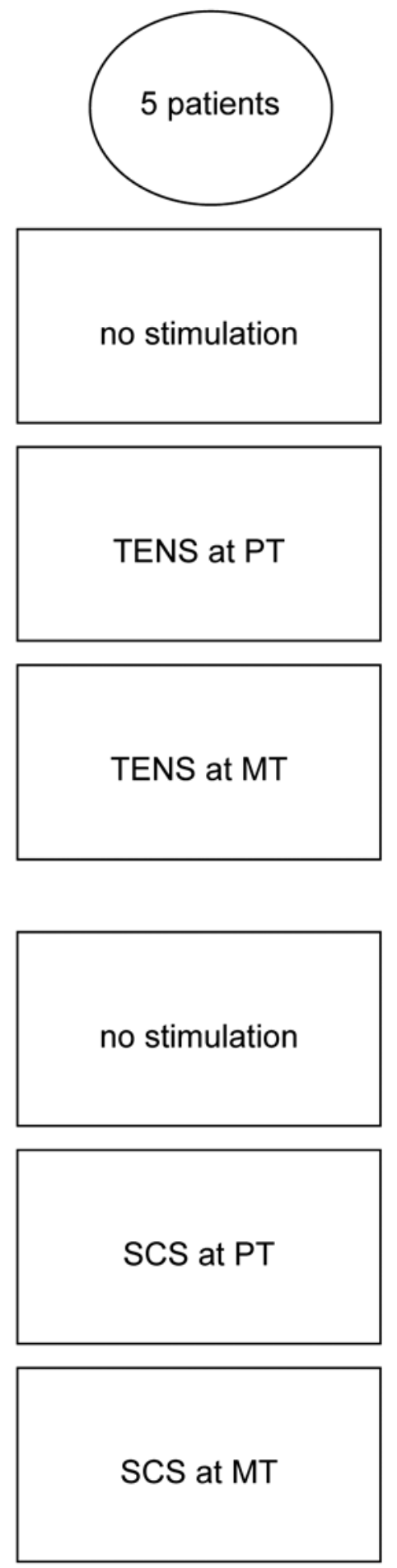
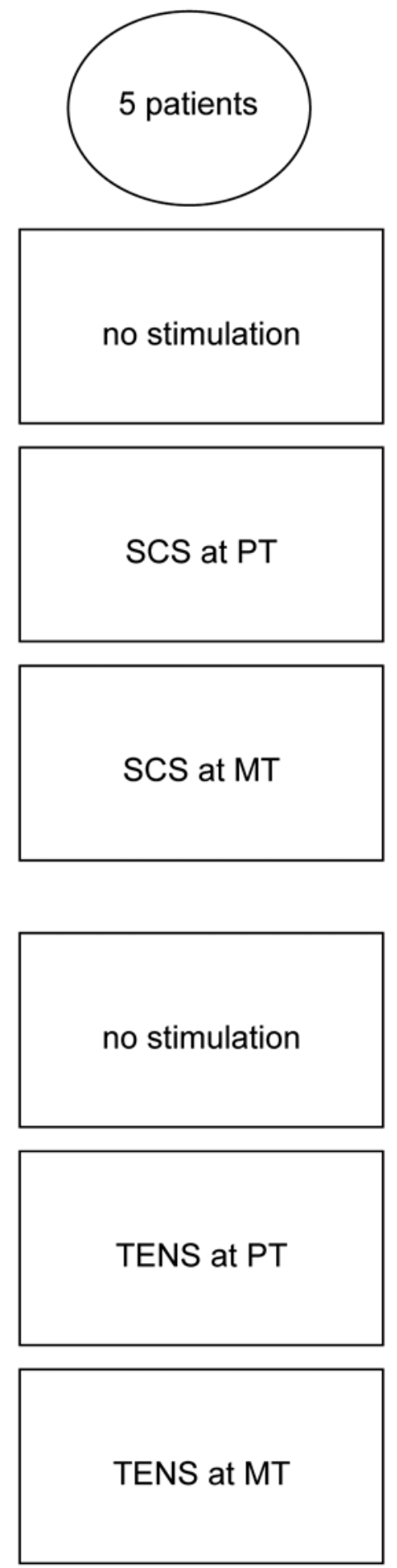

Fig. 1. Flow chart of the procedure: at each stimulation mode 2 recordings, each with 1000 stimuli (duration: appr. 188 sec) were averaged. There was a 2-3 min interval between the first and the second set of measurements. 
Table 1. Thresholds and stimulation parameters in SCS and TENS

\begin{tabular}{|c|c|c|c|c|c|c|c|c|c|c|c|c|}
\hline \multirow[b]{3}{*}{ Pat } & \multicolumn{9}{|c|}{ SCS } & \multicolumn{3}{|c|}{ TENS } \\
\hline & \multirow{2}{*}{ Leads* } & \multicolumn{3}{|c|}{$\begin{array}{c}\text { Perception threshold (PT) } \\
\text { / V }\end{array}$} & \multicolumn{3}{|c|}{ Maximal threshold / V } & \multirow{2}{*}{$\begin{array}{l}\text { Frequency } \\
\quad / \mathbf{H z}\end{array}$} & \multirow{2}{*}{$\begin{array}{c}\text { Impulse } \\
\text { duration/ } \\
\mu \mathrm{s}\end{array}$} & \multirow{2}{*}{$\begin{array}{c}\text { Perception } \\
\text { threshold } \\
(\text { PT) ** }\end{array}$} & \multirow{2}{*}{$\begin{array}{c}\text { Maximal } \\
\text { threshold } \\
(\text { MT) ** }\end{array}$} & \multirow{2}{*}{$\begin{array}{l}\text { Frequency } \\
\quad / \mathrm{Hz}\end{array}$} \\
\hline & & Sitting & Standing & Lying & Sitting & Standing & Lying & & & & & \\
\hline 1 & $4 p$ & 1.3 & 1.8 & 1.7 & 1.8 & 2.5 & 2.3 & 80 & 300 & 21.0 & 56.0 & 80 \\
\hline 2 & $4 p$ & 0.6 & 1.4 & 1.4 & 1.3 & 1.3 & 1.3 & 100 & 270 & 4.5 & 10.5 & 100 \\
\hline 3 & $8 p$ & 1.3 & 1.7 & 1.7 & 1.6 & 2.3 & 2.3 & 100 & 450 & 5.0 & 9.0 & 100 \\
\hline 4 & $8 p$ & 0.4 & 1.6 & 1.6 & 0.7 & 2.6 & 0.9 & 80 & 450 & 4.0 & 5.5 & 80 \\
\hline 5 & $8 p$ & 1.5 & 3.0 & 2.9 & 2.5 & 4.2 & 4.3 & 100 & 360 & 20.0 & 60.0 & 100 \\
\hline 6 & $4 p$ & 1.4 & 3.2 & 3.0 & 2.5 & 5.0 & 4.7 & 130 & 150 & 12.0 & 55.0 & 120 \\
\hline 7 & $8 p$ & 1.8 & 1.6 & 1.6 & 2.8 & 3.1 & 2.8 & 100 & 450 & 11.0 & 38.5 & 100 \\
\hline 8 & $8 \mathrm{p}$ & 2.9 & 3.1 & 3.9 & 4.5 & 4.4 & 4.4 & 100 & 240 & 6.0 & 18.5 & 100 \\
\hline 9 & $4 p$ & 2.2 & 2.5 & 2.6 & 4.9 & 5.0 & 5.0 & 80 & 210 & 42.0 & 56.0 & 80 \\
\hline 10 & $8 p$ & 1.8 & 2.6 & 2.7 & 3.7 & 4.5 & 4.5 & 100 & 240 & 17.0 & 45.0 & 100 \\
\hline mean & $\begin{array}{l}4 \mathrm{x} 4 \mathrm{p} \\
6 \mathrm{x} 8 \mathrm{p}\end{array}$ & 1.5 & 2.3 & 2.3 & 2.6 & 3.5 & 3.3 & 97.0 & 312.0 & 14.3 & 35.4 & 96.0 \\
\hline SD & & 0.7 & 0.7 & 0.8 & 1.4 & 1.3 & 1.5 & 14.9 & 109.7 & 11.7 & 22.2 & 12.6 \\
\hline
\end{tabular}

*all patients had percutaneous type leads: $4 \mathrm{p}=4$ pole, $8 \mathrm{p}=8 \mathrm{pole}$, ${ }^{* *}$ TENS thresholds are displayed in arbitrary units of 0.5 points on a $0-60$ points scale, a value of 60 corresponds to an impulse duration of $200 \mu$ s

statistics were used. Differences between average amplitudes and latencies were tested with the 2-sided Wilcoxon matched pairs test. Spearman correlations were calculated between the pain scores and the percentage of SEP amplitude reduction.

\section{Sample Size Estimation}

With $\alpha=0.05$ and a power of 0.8 , and given a standard deviation (SD) of $0.5 \mu \mathrm{V}$ in the amplitudes of the evoked potentials a detectable alternative of $0.5 \mu \mathrm{V}$ the sample size for the 2-sided Wilcoxon matched pairs test was estimated to be 10 .

\section{Ethics Committee Approval}

This randomized controlled study was approved by the ethics committee of our institution.

\section{Results}

\section{Patients}

Ten patients ( 4 men, 6 women) were included in the study. Mean age was 54.0 years (range 40.7 -- 77.2 years, SD 10.2 years). Mean duration of chronic pain at time of SCS implantation was 5.6 years (range $0.8-14.0$ years, SD 5.8 years). SCS therapy had been applied for mean 3.9 years (range $0.2-12.3$ years, SD 3.8 years) prior to the trial. Diagnoses are listed in Table 2 and baseline stimulator settings are shown in Table 1. All patients were implanted with percutaneous type electrodes. All but 2 patients had non-rechargeable implantable pulse generators (IPG).

\section{Pain Ratings}

Without stimulation, average pain scores were mean 7.05 (range 4.0 - 9.5, SD 1.66). Maximal pain scores (NRS) were mean 7.85 (range 6.0 - 9.5 SD 1.20), minimal pain scores were 5.75 (range 3.0 - 8.0, SD 1.65).

Under stimulation, average mean pain scores were 3.45 (range $0.5-6.0$, SD 1.62), maximal scores were 4.10 (range 1.0 - 7.0, SD 1.77), and minimal pain scores were 2.10 (range $0.0-6.0$, SD 1.82). Average reduction of pain elicited by SCS was 3.60 (50.3\%) (range $2.0-8.0$, SD 1.82) (Table 2). A strong negative correlation was found between the impulse duration and the percentage of pain reduction $(r(9)=-0.7438, P=0.0174)$. There was no correlation between the SEP amplitude reduction and pain reduction elicited by SCS.

\section{SEPS}

The P40N50 amplitude was significantly inhibited by SCS at PT and at MT as well as by TENS at PT and MT. Under SCS at MT amplitudes decreased by mean $48.1 \%$ while under TENS at MT the mean amplitude reduction was $22.9 \%$. There was a statistically significant differ- 
SCS Inhibits Cortical Somatosensory Evoked Potentials

Table 2. Patient characteristics, pain scores and pain reduction elicited by SCS

\begin{tabular}{|c|c|c|c|c|c|c|c|}
\hline Patient & $\begin{array}{c}\text { Age/ } \\
\text { gender }\end{array}$ & Diagnosis & $\begin{array}{c}\text { Duration of } \\
\text { pain at time of } \\
\text { implantation / } \\
\text { years }\end{array}$ & $\begin{array}{l}\text { Duration of } \\
\text { SCS at time of } \\
\text { study / years }\end{array}$ & $\begin{array}{c}\text { Pain } \\
\text { (NRS) } \\
\text { without } \\
\text { SCS }\end{array}$ & $\begin{array}{c}\text { Pain } \\
\text { (NRS) } \\
\text { with SCS }\end{array}$ & $\begin{array}{c}\text { Pain } \\
\text { reduction } \\
/ \%\end{array}$ \\
\hline 1 & $59 / \mathrm{m}$ & FBSS, radiculopathy L5 & 2.9 & 7.1 & 6 & 4 & 33 \\
\hline 2 & $77 / \mathrm{f}$ & FBSS, radiculopathy S1 & 13.6 & 12.3 & 7 & 3.5 & 50 \\
\hline 3 & $47 / f$ & FBSS, radiculopathy L5 & 14.3 & 0.2 & 8 & 5 & 38 \\
\hline 4 & $59 / \mathrm{f}$ & FBSS, radiculopathy L5 & 14.0 & 0.1 & 5 & 3 & 40 \\
\hline 5 & $54 / \mathrm{m}$ & FBSS, radiculopathy L4 and L5, neurinoma & 2.1 & 2.9 & 9.5 & 6 & 37 \\
\hline 6 & $48 / \mathrm{f}$ & FBSS, radiculopathy S1, cauda syndrome & 3.6 & 5.5 & 8.5 & 0.5 & 94 \\
\hline 7 & $51 / \mathrm{f}$ & FBSS, radiculopathy S1, pseudomeningocele & 1.5 & 2.2 & 7.5 & 4.5 & 40 \\
\hline 8 & $57 / \mathrm{m}$ & FBSS, radiculopathy L5, epidural fibrosis & 1.1 & 3.6 & 4 & 2 & 50 \\
\hline 9 & $46 / \mathrm{m}$ & neuropathic knee pain after $2 x$ bursectomy & 0.8 & 4.6 & 8 & 4 & 50 \\
\hline 10 & $40 / \mathrm{f}$ & FBSS, radiculopathy L5 & 2.0 & 0.2 & 7 & 2 & 71 \\
\hline mean & $\begin{array}{c}54.0 \\
(6 f / 4 m)\end{array}$ & & 5.6 & 3.9 & 7.05 & 3.45 & 50.3 \\
\hline
\end{tabular}

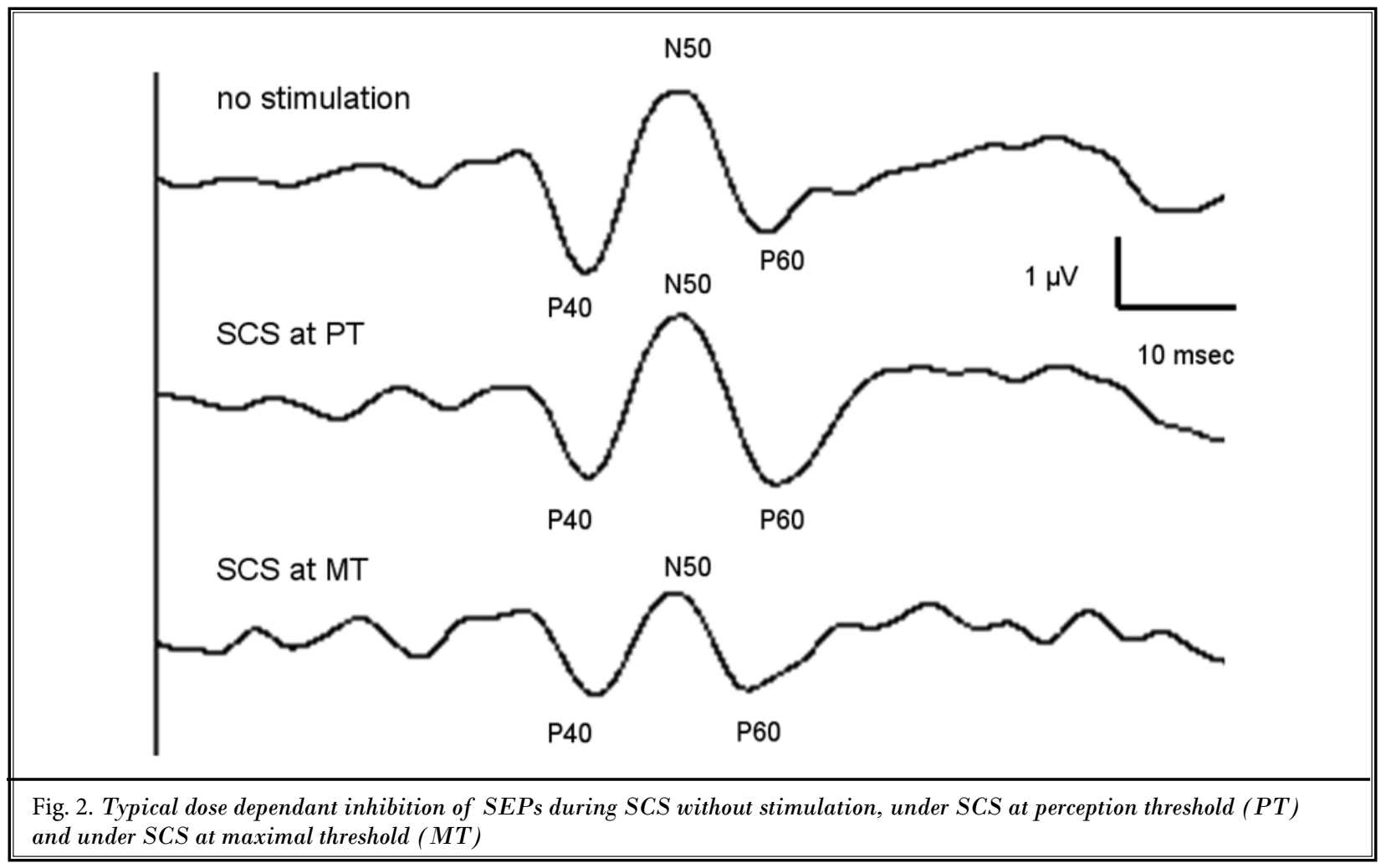

ence between amplitudes under SCS and TENS. Also the N50P60 amplitudes showed a decrease under SCS and under TENS. While under TENS the amplitude reduction was only modest and not statistically significant, the amplitude was reduced by $35.2 \%$ under SCS at MT.
A typical example of the SEP inhibition under SCS is shown in Fig. 2. An overview of the effect of SCS and TENS on SEP amplitudes is given in Table 3.

SEP latencies were not found to be significantly changed under TENS or SCS. Overall, the latencies were 
Table 3. Overview of average amplitudes and their inhibition by SCS /TENS

\begin{tabular}{|c|c|c|c|c|c|c|c|}
\hline & & $\begin{array}{l}\text { no } \\
\text { stimulation } \\
(0)\end{array}$ & $\begin{array}{l}\text { SCS perception } \\
\text { threshold } \\
\text { (PT)* }\end{array}$ & $\begin{array}{l}\text { SCS maximal } \\
\text { threshold } \\
(\mathrm{MT}) * * \\
\end{array}$ & $\begin{array}{l}\text { no } \\
\text { stimulation } \\
(0)\end{array}$ & $\begin{array}{l}\text { TENS } \\
\text { perception } \\
\text { threshold (PT)* }\end{array}$ & $\begin{array}{l}\text { TENS maximal } \\
\text { threshold } \\
(\text { MT)** }\end{array}$ \\
\hline \multirow{5}{*}{ Amplitude P40N50 } & mean & 1.003 & 0.742 & 0.544 & 0.890 & 0.719 & 0.700 \\
\hline & range & $0.38-2.83$ & $0.0-2.21$ & $0.0-1.73$ & $0.25-2.3$ & $0.11-2.08$ & $0.15-2.08$ \\
\hline & median & 0.707 & 0.553 & 0.389 & 0.696 & 0.555 & 0.520 \\
\hline & SD & 0.757 & 0.700 & 0.500 & 0.670 & 0.606 & 0.578 \\
\hline & SE & 0.239 & 0.221 & 0.158 & 0.212 & 0.192 & 0.183 \\
\hline \multicolumn{8}{|l|}{$P$} \\
\hline 0 vs PT & & \multicolumn{2}{|c|}{0.0039} & & \multicolumn{2}{|c|}{0.0039} & \\
\hline PT vs MT & & & \multicolumn{2}{|c|}{0.0742} & & \multicolumn{2}{|c|}{0.7695} \\
\hline 0 vs MT & & \multicolumn{3}{|c|}{0.0020} & \multicolumn{3}{|c|}{0.0039} \\
\hline 0 vs 0 & & \multicolumn{4}{|c|}{0.1289} & & \\
\hline PT (SCS vs TENS) & & & \multicolumn{4}{|c|}{0.7695} & \\
\hline MT (SCS vs TENS) & & & & \multicolumn{4}{|c|}{0.0059} \\
\hline \multirow{5}{*}{ Amplitude N50P60 } & mean & 0.799 & 0.701 & 0.575 & 0.753 & 0.751 & 0.677 \\
\hline & range & $0.28-2.07$ & $0.0-2.15$ & $0.0-1.67$ & $0.22-2.11$ & $0.16-2.01$ & $0.11-2.01$ \\
\hline & median & 0.574 & 0.528 & 0.423 & 0.506 & 0.569 & 0.447 \\
\hline & SD & 0.555 & 0.644 & 0.493 & 0.594 & 0.607 & 0.609 \\
\hline & SE & 0.176 & 0.204 & 0.156 & 0.188 & 0.192 & 0.192 \\
\hline \multicolumn{8}{|l|}{$P$} \\
\hline 0 vs PT & & \multicolumn{2}{|c|}{0.1055} & & \multicolumn{2}{|r|}{0.9219} & \\
\hline PT vs MT & & & \multicolumn{2}{|c|}{0.1289} & & \multicolumn{2}{|c|}{0.1055} \\
\hline 0 vs MT & & \multicolumn{3}{|c|}{0.0020} & \multicolumn{3}{|c|}{0.1055} \\
\hline 0 vs 0 & & \multicolumn{4}{|c|}{0.3223} & & \\
\hline PT (SCS vs TENS) & & & \multicolumn{4}{|c|}{0.2754} & \\
\hline MT (SCS vs TENS) & & & & \multicolumn{4}{|c|}{0,1602} \\
\hline
\end{tabular}

* measurement at the lowest SCS or TENS voltage the patient was able to perceive, ${ }^{* *}$ measurement at the highest SCS or TENS voltage that was not regaded as painful, bold $=<0.05$

in the range reported in the literature (21). There were no statistically significant differences between the P40, N50, and P60 latencies under TENS, under SCS, and without stimulation (Table 4).

\section{Discussion}

The present study shows that cortical SEP amplitudes are significantly inhibited by SCS. Stimulation at PT as well as stimulation at MT led to a statistically significant inhibition of the SEP amplitude. There was also a tendency towards statistical significance regarding the difference between SEP amplitudes under SCS at PT and SCS at MT, which suggests a dose dependency of SEP amplitude inhibition by SCS. The degree of SEP amplitude inhibition did not correlate with the degree of pain relief reported by the patients. Inhibition of SEP amplitudes under TENS, however, was weaker than that elicited by SCS. The difference between the SEP amplitudes under SCS at MT and under TENS at MT was statistically significant. Thus, it can be concluded that, at the same level of intensity relative to maximal threshold, SCS exerts a stronger inhibition of SEP amplitudes than TENS. The average percentage of amplitude reduction under SCS was twice as high as it was under TENS.

The SEP amplitude reduction exerted by SCS has been described in a number of studies $(12-14,22,23)$.

A neurophysiological mechanism, termed collision of impulses $(14,24)$, was proposed as a putative mechanism to account for amplitude inhibition elicited by SCS. According to this theory, 2 action potentials travelling 
Table 4. Overview over average latencies P40 / N50 an N60.

\begin{tabular}{|c|c|c|c|c|c|c|c|}
\hline & & \begin{tabular}{|l|} 
no \\
stimulation \\
$(0)$
\end{tabular} & $\begin{array}{l}\text { SCS perception } \\
\text { threshold } \\
(\mathrm{PT})^{*}\end{array}$ & $\begin{array}{l}\text { SCS maximal } \\
\text { threshold } \\
(\mathrm{MT})^{* *}\end{array}$ & $\begin{array}{l}\text { no } \\
\text { stimulation } \\
(\mathbf{0})\end{array}$ & $\begin{array}{l}\text { TENS } \\
\text { perception } \\
\text { threshold (PT)* }\end{array}$ & $\begin{array}{l}\text { TENS maximal } \\
\text { threshold } \\
(\text { MT)** }\end{array}$ \\
\hline \multirow[t]{5}{*}{ Latency P40 } & mean & 41.22 & 41.51 & 41.98 & 41.93 & 42.37 & 41.91 \\
\hline & range & $35.83-50.28$ & $36.41-49.05$ & $36.75-50.03$ & $37.07-50.65$ & $37.45-51.45$ & $36.03-50.13$ \\
\hline & median & 40.18 & 40.69 & 40.40 & 40.18 & 41.87 & 40.99 \\
\hline & SD & 5.125 & 4.946 & 4.779 & 4.920 & 4.914 & 4.863 \\
\hline & SE & 1.621 & 1.564 & 1.511 & 1.556 & 1.554 & 1.538 \\
\hline \multirow[t]{5}{*}{ Latency N50 } & mean & 50.80 & 49.59 & 49.83 & 49.63 & 49.72 & 49.47 \\
\hline & range & $40.62-62.90$ & $40.33-57.62$ & $40.76-56.46$ & $40.47-57.77$ & $40.91-58.50$ & $41.35-57.63$ \\
\hline & median & 52.72 & 49.49 & 51.10 & 51.54 & 51.62 & 50.37 \\
\hline & SD & 7.086 & 5.782 & 5.423 & 5.560 & 5.934 & 5.257 \\
\hline & SE & 2.241 & 1.828 & 1.715 & 1.758 & 1.877 & 1.662 \\
\hline \multirow[t]{5}{*}{ Latency P60 } & mean & 58.20 & 58.44 & 58.24 & 59.31 & 57.76 & 57.46 \\
\hline & range & $45.75-68.62$ & $45.75-69.79$ & $48.10-71.11$ & $46.63-69.50$ & $46.78-67.89$ & $46.63-66.86$ \\
\hline & median & 58.11 & 58.27 & 59.06 & 58.37 & 57.87 & 57.32 \\
\hline & SD & 6.869 & 6.791 & 6.596 & 6.065 & 6.047 & 5.827 \\
\hline & $\mathrm{SE}$ & 2.172 & 2.148 & 2.086 & 1.918 & 1.912 & 1.843 \\
\hline
\end{tabular}

${ }^{*}$ measurement at the lowest SCS or TENS voltage the patient was able to perceive, ${ }^{* *}$ measurement at the highest SCS or TENS voltage that was not considered painful, no statistically significant differences between mean latencies under the different stimulation modes were detected

in opposite directions would neutralize each other at the moment of their collision. This might partly explain the smaller amplitude inhibition under TENS.

However, a subcortical contribution to the amplitude decreases was considered improbable by Polacek et al (12). They argued that decreased somatosensory input does not explain the increased functional activation in various cortical structures during SCS (25-27). Determining which mechanism might account for SEP inhibition under SCS was beyond the scope of this study; probably both of the above described mechanisms act in concert.

The data of the present study suggest a dose dependency of the SCS inhibition elicited by SCS. Although recent clinical studies have found a dose dependent clinical pain-relieving effect of SCS, and a measurable effect was even observed when stimulation was performed below threshold $(15,28)$ for the inhibitory effects on SEPs elicited by SCS, dose dependency has not yet been confirmed. Moreover, it remains unclear whether SEP inhibition by neurostimulation is correlated to clinical pain relief. The present study failed to demonstrate such a correlation.

Previous studies have shown that TENS can also reduce SEP amplitudes (29-30). The present study compared inhibitory effects on SEPs and found those elicit- ed by SCS greater than those affected by TENS. It could be objected that, in contrast to SCS, TENS often does not cover the whole painful area and might thus have a smaller pain-relieving effect. This, however, should not influence the extent of SEP amplitude reduction, as the area of SEP recording was completely covered in both TENS and SCS. Moreover in both instances, the same stimulation intensities were chosen relative to PT and MT. A more conclusive explanation for the stronger SEP inhibition under SCS might be given by the above-mentioned collision of impulses mechanism. This, however, implies that stimulation is applied proximal to the pain source (or the SEP stimulation electrode). In the case of TENS, however, stimulation was applied distallyto the SEP stimulation electrode. Moreover, animal models have shown that SCS acts via a couple of mechanisms at the segmental level, thus at the location where SCS is applied. Under SCS, attenuation of the pain-induced hyperexcitability of wide dynamic range (WDR) neurons has been found (31). It is believed that increased $\gamma$-aminobutyric acid (GABA) release (32-33) from inhibitory interneurons account for that effect, particularly by activation of the GABA-B receptor (34). There also seems to be some contribution of the cholinergic system to SCS effects, as a release of acetylcholine in the dorsal horn was observed and later attributed to activa- 
tion of the muscarinic M4 receptor (35). Unlike dorsal column stimulation, dorsal root stimulation failed in a recent study to inhibit windup in WDR neurons in neuropathic conditions in a rodent model (36). This may point towards a neurobiological difference between the mechanisms of SCS and peripheral nerve stimulation as in TENS. An additional mechanism which gives a possible explanation for the stronger SEP inhibition by SCS, is its effect on descending serotonergic fibers (37).

Similar to the results described by Buonocore et al (14), the inhibitory effects of SCS and TENS were more pronounced in the present study at the amplitude P40N50 than at the amplitude N50P60. The P40 is generated in the area $3 b$, the primary sensible field on the medial side of the gyrus postcentralis. The P60 is thought to be generated symmetrically within the convexity of the parietal cortex. The generators of the P60 thus have a much bigger spatial extension than those of the P40 wave (38). This might lead to a more unspecific response, limiting its clinical significance. The amplitude P40N50 is the only cortical response regarded as suitable for clinical purposes (39).

In the present study, as in others $(14,29)$, the SEP latencies were not influenced by stimulation. Latencies are impacted when the saltatory conduction of a nerve is compromised, a phenomenon which can be initiated by various pathological processes, particularly demyelinating diseases. As nerve fibers and pericarions are not influenced by neurostimulation, an effect on latencies cannot be expected.

Some limitations of the present study have to be addressed. First, the mechanism of regulation in the SCS and TENS devices are different. While the impulse duration was fixed and intensity of stimulation was regulated through the voltage in use in the SCS devices in our study, the intensity of stimulation was regulated with the impulse duration in the TENS devices. Thus the exact shape of the single stimulus in SCS and TENS may have been unequal. However, in both instances, stimulation modes which are used in routine clinical settings were applied, the frequencies of stimulation were the same and both TENS and SCS were applied at the same intensities relative to $\mathrm{PT}$ and $\mathrm{MT}$.

The difference between PT and MT in SCS was not statistically significant but showed a tendency towards significance. This means that the dose dependency of SEP amplitude inhibition only seems probable but is not proven. Apparently, the study is slightly underpowered to provide that evidence. The number of patients is relatively small, but it was based on a sample size calculation. With this sample size, 2 of the 3 principle questions could be answered.

In order to prove a correlation between SEP inhibition and the pain-relieving effect of SCS, pain scores collected directly under stimulation might have been more meaningful. Most patients, however, had difficulties in distinguishing the unpleasantness caused by SEP stimulation and their usual pain, so that these (direct) pain scores were not reliable. We therefore chose to ask the patients for a more global estimation of their pain with and without SCS.

\section{Conclusion}

In conclusion, SCS exerts a significantly stronger inhibition of SEP amplitudes than TENS. The present data hint at a dose dependency of SCS-induced SEP amplitude inhibition. No clear correlation was found between SEP amplitude inhibition and pain relief by SCS. Further studies should also focus on electrophysiological effects of subcutaneous stimulation.

\section{References}

1. Cameron T. Safety and efficacy of spinal cord stimulation for the treatment of chronic pain: A 20-year literature review. J Neurosurg 2004; 100:254-267.

2. Meglio M, Cioni B, Prezioso A, Talamonti G. Spinal cord stimulation (SCS) in the treatment of postherpetic pain. Acta Neurochir Suppl (Wien) 1989; 46:65-66.

3. De La Porte C, Van de Kelft E. Spinal cord stimulation in failed back surgery syndrome. Pain 1993; 52:55-61.
4. Hassenbusch SJ, Stanton-Hicks $M$, Covington EC. Spinal cord stimulation versus spinal infusion for low back and leg pain. Acta Neurochir Suppl 1995; 64:109-115.

5. Ohnmeiss DD, Rashbaum RF, Bogdanffy GM. Prospective outcome evaluation of spinal cord stimulation in patients with intractable leg pain. Spine (Phila Pa 1976) 1996; 21:1344-1350; discussion 1351.

6. Kumar K, Taylor RS, Jacques L, Eldabe
S, Meglio M, Molet J, Thomson S, O'Callaghan J, Eisenberg E, Milbouw G, Buchser E, Fortini G, Richardson J, North RB. Spinal cord stimulation versus conventional medical management for neuropathic pain: A multicentre randomised controlled trial in patients with failed back surgery syndrome. Pain 2007; 132:179-188.

7. Kemler MA, Reulen JP, Barendse $G A$, van Kleef $M$, de Vet $H C$, van den Wildenberg FA. Impact of spinal cord 
stimulation on sensory characteristics in complex regional pain syndrome type I: A randomized trial. Anesthesiology 2001; 95:72-80.

8. Harke $\mathrm{H}$, Gretenkort $\mathrm{P}$, Ladleif $\mathrm{HU}$, Rahman S. Spinal cord stimulation in sympathetically maintained complex regional pain syndrome type I with severe disability. A prospective clinical study. Eur J Pain 2005; 9:363-373.

9. Kemler MA, de Vet HC, Barendse GA, van den Wildenberg FA, van Kleef $M$. Spinal cord stimulation for chronic reflex sympathetic dystrophy--fiveyear follow-up. N Engl J Med 2006; 354:2394-2396.

10. Harke H, Gretenkort P, Ladleif HU, Koester P, Rahman S. Spinal cord stimulation in postherpetic neuralgia and in acute herpes zoster pain. Anesth Analg 2002; 94:694-700; table of contents.

11. Linderoth B, Meyerson BA. Spinal cord stimulation: Exploration of the physiological basis of a widely used therapy. Anesthesiology 2010; 113:1265-1267.

12. Polacek H, Kozak J, Vrba I, Vrana J, Stancak A. Effects of spinal cord stimulation on the cortical somatosensory evoked potentials in failed back surgery syndrome patients. Clin Neurophysiol 2007; 118:1291-1302.

13. de Andrade DC, Bendib B, Hattou M, Keravel Y, Nguyen JP, Lefaucheur JP. Neurophysiological assessment of spinal cord stimulation in failed back surgery syndrome. Pain 2010; 150:485-491.

14. Buonocore M, Bodini A, Demartini L, Bonezzi C. Inhibition of somatosensory evoked potentials during spinal cord stimulation and its possible role in the comprehension of antalgic mechanisms of neurostimulation for neuropathic pain. Minerva Anestesiol 2012; 78:297-302.

15. Wolter T, Kiemen A, Porzelius C, Kaube $\mathrm{H}$. Effects of sub-perception threshold spinal cord stimulation in neuropathic pain: A randomized controlled doubleblind crossover study. Eur J Pain 2012; 16:648-655.

16. Verrills P, Vivian D, Mitchell B, Barnard A. Peripheral nerve field stimulation for chronic pain: 100 cases and review of the literature. Pain Med 2011; 12:1395-1405.

17. Yakovlev AE, Resch BE, Yakovleva VE. Peripheral nerve field stimulation in the treatment of postlaminectomy syn- drome after multilevel spinal surgeries. Neuromodulation 2011; 14:534-538; discussion 538.

18. Goyal GN, Gupta D, Jain R, Kumar $S$, Mishra S, Bhatnagar S. Peripheral nerve field stimulation for intractable post-thoracotomy scar pain not relieved by conventional treatment. Pain Pract 2010; 10:366-369.

19. Barolat G. Peripheral subcutaneous stimulation for intractable abdominal pain. Prog Neurol Surg 2011; 24:70-76.

20. Kouroukli I, Neofytos D, Panaretou V, Zompolas V, Papastergiou D, Sanidas G, Papavassilopoulou T, Georgiou L. Peripheral subcutaneous stimulation for the treatment of intractable postherpetic neuralgia: Two case reports and literature review. Pain Pract 2009; 9:225-229.

21. Miura T, Sonoo M, Shimizu T. Establishment of standard values for the latency, interval and amplitude parameters of tibial nerve somatosensory evoked potentials (SEPs). Clin Neurophysiol 2003; 114:1367-1378.

22. Larson SJ, Sances A, Jr., Riegel DH, Meyer GA, Dallmann DE, Swiontek T. Neurophysiological effects of dorsal column stimulation in man and monkey. J Neurosurg 1974; 41:217-223.

23. Doerr M, Krainick JU, Thoden U. Pain perception in man after long term spinal cord stimulation. J Neurol 1978; 217:261-270.

24. Kimura J. Collision technique. Physiologic block of nerve impulses in studies of motor nerve conduction velocity. Neurology 1976; 26:680-682.

25. Kiriakopoulos ET, Tasker RR, Nicosia S, Wood ML, Mikulis DJ. Functional magnetic resonance imaging: A potential tool for the evaluation of spinal cord stimulation: Technical case report. Neurosurgery 1997; 41:501-504.

26. Rasche D, Siebert S, Stippich C, Kress B, Nennig E, Sartor K, Tronnier VM. [Spinal cord stimulation in failedback-surgery-syndrome. Preliminary study for the evaluation of therapy by functional magnetic resonance imaging (fMRI)]. Schmerz 2005; 19:497-500, 502-505.

27. Stancak A, Kozak J, Vrba I, Tintera J, Vrana J, Polacek H, Stancak M. Functional magnetic resonance imaging of cerebral activation during spinal cord stimulation in failed back surgery syndrome patients. Eur J Pain 2008; 12:137-148.

28. Eddicks S, Maier-Hauff K, Schenk M, Muller A, Baumann G, Theres $H$. Thoracic spinal cord stimulation improves functional status and relieves symptoms in patients with refractory angina pectoris: The first placebo-controlled randomised study. Heart 2007; 93:585-590.

29. Golding JF, Ashton $H$, Marsh $R$, Thompson JW. Transcutaneous electrical nerve stimulation produces variable changes in somatosensory evoked potentials, sensory perception and pain threshold: Clinical implications for pain relief. J Neurol Neurosurg Psychiatry 1986; 49:1397-1406.

30. Akyuz G, Guven Z, Ozaras N, Kayhan $O$. The effect of conventional transcutaneous electrical nerve stimulation on somatosensory evoked potentials. Electromyogr Clin Neurophysiol 1995; 35:371-376.

31. Yakhnitsa V, Linderoth B, Meyerson BA. Spinal cord stimulation attenuates dorsal horn neuronal hyperexcitability in a rat model of mononeuropathy. Pain 1999; 79:223-233.

32. Linderoth B, Stiller CO, Gunasekera L, O'Connor WT, Ungerstedt U, Brodin E. Gamma-aminobutyric acid is released in the dorsal horn by electrical spinal cord stimulation: An in vivo microdialysis study in the rat. Neurosurgery 1994; 34:484-488; discussion 488-489.

33. Stiller CO, Cui JG, O'Connor WT, Brodin E, Meyerson BA, Linderoth B. Release of gamma-aminobutyric acid in the dorsal horn and suppression of tactile allodynia by spinal cord stimulation in mononeuropathic rats. Neurosurgery 1996; 39:367-374; discussion 374-375.

34. Cui JG, Meyerson BA, Sollevi A, Linderoth B. Effect of spinal cord stimulation on tactile hypersensitivity in mononeuropathic rats is potentiated by simultaneous $\mathrm{GABA}(\mathrm{B})$ and adenosine receptor activation. Neurosci Lett 1998; 247:183-186.

35. Schechtmann G, Song Z, Ultenius C, Meyerson BA, Linderoth B. Cholinergic mechanisms involved in the pain relieving effect of spinal cord stimulation in a model of neuropathy. Pain 2008; 139:136-145.

36. Guan Y, Wacnik PW, Yang F, Carteret AF, Chung CY, Meyer RA, Raja SN. Spinal cord stimulation-induced analgesia: Electrical stimulation of dorsal 
column and dorsal roots attenuates dorsal horn neuronal excitability in neuropathic rats. Anesthesiology 2010; 113:1392-1405.

37. Song Z, Ultenius C, Meyerson BA Linderoth B. Pain relief by spinal cord stimulation involves serotonergic mechanisms: An experimental study in a rat model of mononeuropathy. Pain 2009; 147:241-248.

38. Maurer K, Lang N, Eckert J. Praxis der Evozierten Potentiale. Steinkopf, Darmstadt, 2005 .
39. Cruccu G, Aminoff MJ, Curio G, Guerit JM, Kakigi R, Mauguiere F, Rossini PM, Treede RD, Garcia-Larrea L. Recommendations for the clinical use of somatosensory-evoked potentials. Clin Neurophysiol 2008; 119:1705-1719. 